\title{
Risk factors for treatment outcome of suspected microbial keratitis
}

\author{
Nigel Morlet, Darwin Minassian, Jeremy Butcher, and the Ofloxacin Study Group*
}

\begin{abstract}
Background-Primary treatment for suspected microbial keratitis is generally successful. Although risks such as contact lens use are well recognised as causative factors for microbial keratitis, little is known about the risk factors that influence treatment outcome. The present study evaluates the risk factors assessed at diagnosis as prognostic indicators of primary treatment failure.
\end{abstract}

Methods-Patients were prospectively enrolled in the ofloxacin treatment trial and data concerning symptoms, treatments, past and concurrent eye disease were collected along with the measurement of corneal ulcer size at the slit lamp. All patients were scraped for microbiological investigation, and treated with either ofloxacin $(0.3 \%)$ or standard therapy of fortified cefuroxime and gentamicin drops. Treatment success was complete healing of the ulcer with zero dimensions of the epithelial defect within 2 weeks of start of treatment. The important prognostic indicators were selected by comparison among those who failed treatment, had delayed healing, or were culture positive with other patients using univariate and stratified analysis. These were then used in a Poisson model for multiple regression analysis to estimate the relative risk of the main prognostic variables.

Results-Of the 118 patients enrolled in the study, 14 were identified as primary treatment failures, 17 had slow healing, and 15 indolent ulcers. There were 49 culture positive patients. The multivariate analysis identified that large culture positive ulcers in patients 60 years or older had 5.5 times the risk of primary treatment failure $(p<0.001)$. Significant predictors of slow healing were previous ocular disease and a positive culture; significant predictors of indolent ulceration were previous ocular disease and steroid use at diagnosis; the main predictor of a culture positive result was ulcer size.

Conclusions-Elderly patients with large ulcers were more likely to be culture positive, fail primary therapy, and require surgical intervention. A positive microbial culture provided prognostic information regardless of the organism isolated. However, this information was of less value for those with small ulcers and for younger patients.

(Br f Ophthalmol 1999;83:1027-1031)
Primary treatment of suspected microbial keratitis with either extemporaneously prepared fortified antibiotics or commercially available topical fluoroquinolones results in cure in around $90 \%$ of cases. ${ }^{1-6}$ Although risks for the development of microbial keratitis such as contact lens use and ocular surface disease are well recognised, ${ }^{78}$ little is known about how these and other risks may influence treatment outcome. Previous retrospective studies have suggested that ulcer size may be important but data quantifying the relative risks are not available. ${ }^{910}$ Distinguishing those at high risk of primary treatment failure or those likely to have a positive culture would facilitate rationalisation of microbial investigation, the value of which has been questioned in a series of papers by McDonnell et al. ${ }^{11-13}$ In this prospective study, risk factors assessed at diagnosis were evaluated as prognostic indicators with the use of multivariate analysis.

\section{Methods}

With ethics committee approval, patients were recruited over a 12 month period as part of the ofloxacin treatment trial for the initial management of suspected bacterial keratitis at Moorfields Eye Hospital and Manchester Royal Eye Hospital. Both centres enrolled predominantly primary care patients, some clinic patients, and a small number of tertiary referrals.

\section{DEFINITIONS}

Suspected bacterial keratitis was defined as a corneal epithelial defect of any size with an infiltration of the underlying stroma thought to be caused by infection. Those suspected of having fungal, amoebic, or viral keratitis, those with a known hypersensitivity to any of the trial drugs, and patients unwilling to participate in the study were not recruited.

Treatment success was defined as complete healing of the ulcer within 2 weeks of commencement of therapy. Primary treatment failure was defined as an increase in ulcer size or infiltrate, perforation, or when an organism resistant to any of the trial drops was isolated. Delayed healing was defined as failure of complete epithelialisation of the ulcer following 2 weeks of treatment, and was further subclassified into slow healing ulcers (those with progressive but delayed healing) and indolent ulcers (those with a persistent epithelial defect that remained unchanged in size).

HISTORY, EXAMINATION, AND INVESTIGATION After obtaining informed consent, the enrolled patients were questioned about the duration of symptoms before presentation, past and concurrent eye disease, and specific ophthalmic
Accepted for publication 4 May 1999 $\star$ Members listed at the end

Correspondence to: J K G Dart, Moorfields Eye Hospital, City Road, London 
Table 1 Frequency of primary treatment failure, delayed healing, and indolent ulceration in various subgroups of patients presenting with suspected microbial keratitis

\begin{tabular}{|c|c|c|c|c|c|}
\hline Characterisitic at diagnosis & & Number & $\begin{array}{l}\% \text { Primary } \\
\text { treatment failure } \\
(n=14)\end{array}$ & $\begin{array}{l}\% \text { Slow } \\
\text { healing ulcers } \\
(n=17)\end{array}$ & $\begin{array}{l}\% \text { Indolent } \\
\text { ulcers } \\
(n=15)\end{array}$ \\
\hline \multicolumn{6}{|l|}{ Age (years) } \\
\hline$<60$ & & 76 & 1.3 & 7.9 & 5.3 \\
\hline $60+$ & & 42 & 31.0 & 26.2 & 26.2 \\
\hline \multicolumn{6}{|l|}{ Sex } \\
\hline Males & & 69 & 10.1 & 11.6 & 13.0 \\
\hline Females & & 49 & 14.3 & 18.4 & 12.2 \\
\hline \multicolumn{6}{|l|}{ Ulcer size $\left(\mathrm{mm}^{2}\right)^{\star}$} \\
\hline \multicolumn{6}{|l|}{ Culture positive } \\
\hline$<5 \mathrm{~mm}^{2}$ & & 23 & 8.7 & 17.8 & 8.7 \\
\hline $5+\mathrm{mm}^{2}$ & & 26 & 42.3 & 34.6 & 30.8 \\
\hline \multicolumn{6}{|l|}{ Culture negative } \\
\hline$<5 \mathrm{~mm}^{2}$ & & 60 & 0.0 & 3.3 & 6.7 \\
\hline $5+\mathrm{mm}^{2}$ & & 9 & 11.1 & 22.2 & 11.1 \\
\hline \multicolumn{6}{|l|}{ Hypopyon } \\
\hline Present & & 15 & 33.3 & 26.7 & 26.7 \\
\hline Absent & & 103 & 8.7 & 12.6 & 10.7 \\
\hline \multicolumn{6}{|c|}{ Symptom to treatment interval (days) } \\
\hline$<4$ & & 68 & 7.4 & 10.3 & 10.3 \\
\hline $4+$ & & 44 & 13.6 & 20.5 & 13.6 \\
\hline \multicolumn{6}{|l|}{ Previous disease $†$} \\
\hline \multirow[t]{2}{*}{ Corneal } & present & 38 & 28.9 & 21.1 & 26.3 \\
\hline & absent & 80 & 3.8 & 11.3 & 6.3 \\
\hline \multirow[t]{2}{*}{ Cataract } & present & 11 & 27.3 & 36.4 & 36.4 \\
\hline & absent & 107 & 10.3 & 12.1 & 10.3 \\
\hline \multirow[t]{2}{*}{ Glaucoma } & present & 11 & 18.2 & 27.3 & 36.4 \\
\hline & absent & 107 & 11.2 & 13.1 & 10.3 \\
\hline \multirow[t]{2}{*}{ Other } & present & 20 & 15.0 & 30.0 & 25.0 \\
\hline & absent & 98 & 11.2 & 11.2 & 10.2 \\
\hline Any & & 62 & 21.0 & 25.8 & 22.6 \\
\hline None & & 56 & 1.8 & 1.8 & 1.8 \\
\hline \multicolumn{6}{|l|}{ Concurrent factors $\dagger$} \\
\hline \multirow[t]{2}{*}{ Contact lens } & present & 46 & 2.2 & 6.5 & 2.2 \\
\hline & absent & 72 & 18.1 & 19.4 & 19.4 \\
\hline \multirow[t]{2}{*}{ Ocular surface disease } & present & 7 & 42.9 & 14.3 & 57.1 \\
\hline & absent & 111 & 9.9 & 14.4 & 9.9 \\
\hline Any & & 83 & 12.0 & 15.7 & 13.3 \\
\hline None & & 35 & 11.4 & 11.4 & 11.4 \\
\hline \multicolumn{6}{|l|}{ Current treatment $\dagger$} \\
\hline \multirow{2}{*}{ Antibiotics } & present & 26 & 19.2 & 11.5 & 15.4 \\
\hline & absent & 92 & 9.8 & 15.2 & 12.0 \\
\hline \multirow[t]{2}{*}{ Steroids } & present & 19 & 31.6 & 36.8 & 36.8 \\
\hline & absent & 99 & 8.1 & 10.1 & 8.1 \\
\hline \multicolumn{6}{|l|}{ Culture result } \\
\hline Positive & & 49 & 26.5 & 26.5 & 20.4 \\
\hline Negative & & 69 & 1.4 & 5.8 & 7.2 \\
\hline
\end{tabular}

^Ulcer size calculated as product of maximum horizontal and vertical lengths in $\mathrm{mm}$.

tThese categories are not exclusive as some patients had more than one disorder or treatment.

treatment at the time of presentation. The presence of any hypopyon was noted and the size of the corneal ulcer was measured in two dimensions using the graduated slit beam of a HaagStreit slit lamp. Firstly, the longest dimension of the defect was determined then the dimension perpendicular to the first was measured.

The lesion was scraped in each patient following administration of unpreserved topical amethocaine $1 \mathrm{mg} / \mathrm{ml}$. Using sterile disposable 21 gauge hypodermic needles, the ulcer was debrided and the base and edges scraped. A fresh needle was used on each occasion to directly inoculate a blood or chocolate agar plate, Robertson's cooked meat broth, thioglycolate broth, brain-heart infusion broth, a Sabouraud's agar slope or plate, and slides for Gram and other stains. Following incubation any positive cultures were characterised and were tested for antibiotic sensitivity using the disc diffusion method.

\section{TREATMENT}

Ofloxacin $3 \mathrm{mg} / \mathrm{ml}$ drops (Exocin 0.3\%, Allergan) or gentamicin $15 \mathrm{mg} / \mathrm{ml}$ drops and cefuroxime $50 \mathrm{mg} / \mathrm{ml}$ drops were prescribed. Patients were instructed to apply one of each of the drops each hour day and night for 48 hours, reducing to hourly day only for a further 3 days, then the frequency of application was reduced to four times a day until the ulcer was healed. Reviews were arranged at least weekly and as the clinical situation necessitated and treatment was ceased once the ulcer was epithelialised. At each review the patient's ulcer size was measured and they were examined for evidence of drug toxicity.

ANALYSIS OF FINDINGS

Potential prognostic factors were compared among those who failed treatment, had delayed healing, or were culture positive with the other patients. These included age, sex, size of ulcer at randomisation, past and concurrent morbidity, culture results, current antibiotic or steroid treatment, and the interval between onset of symptoms and start of treatment. Ulcer size (in $\mathrm{mm}^{2}$ ) was derived from the product of the dimensions measured as described. Initial scrutiny of the risk factors through univariate and stratified analysis was carried out to identify and select important prognostic variables for subsequent inclusion in the regression

Table 2 Clinical characteristics of the 14/118 patients who failed primary therapy of suspected microbial keratitis

\begin{tabular}{|c|c|c|c|c|c|c|c|c|c|c|c|c|}
\hline$I D$ & Age & Sex & Diagnoses & Drops & Size & Therapy & $\begin{array}{l}\text { Culture and sensitivit } \\
\text { antibiotics }\end{array}$ & & $\begin{array}{l}\text { Days } \\
\text { treated }\end{array}$ & $\begin{array}{l}\text { Size at } \\
\text { change }\end{array}$ & Complication & Outcome \\
\hline $1 / 10$ & 73 & $\mathrm{~F}$ & HSV & Steroid & $6.5 \times 7.5$ & Oflox & Moraxella sp & $\mathrm{n} / \mathrm{a}$ & 1 & $6.5 \times 7.5$ & $\begin{array}{l}\text { perforation, } \\
\text { slow healing }\end{array}$ & $\begin{array}{l}\text { self sealed, } \\
\text { tarsorrhaphy }\end{array}$ \\
\hline $1 / 83$ & 81 & $\mathrm{~F}$ & OCP & Hypromellose & $3.0 \times 2.0$ & Oflox & $S$ aureus & yes & 4 & $5.0 \times 2.0$ & perforation & PK (@12/7) \\
\hline $2 / 22$ & 79 & M & Rosacea & & $3.5 \times 3.0$ & Oflox & Pneuтососсиs & yes & 3 & $4.0 \times 4.6$ & nil & healed \\
\hline $2 / 5$ & 67 & M & $\begin{array}{l}\text { V and VII nerve palsy } \\
\text { exposure }\end{array}$ & & $4.5 \times 2.5$ & Oflox & Pneumococcus & yes & 3 & $4.0 \times 2.0$ & nil & $\begin{array}{l}\text { permanent } \\
\text { tarsorrhaphy }\end{array}$ \\
\hline $1 / 18$ & 74 & M & $\mathrm{AKC}$ & & $1.0 \times 0.5$ & Oflox & Candida & no & 2 & $3.0 \times 2.0$ & indolent & healed \\
\hline $2 / 13$ & 70 & $\mathrm{~F}$ & $\begin{array}{l}\text { PK } 3 / 52 \text { for } \\
\text { perforated bacterial } \\
\text { ulcer }\end{array}$ & $\begin{array}{l}\text { Steroid } \\
\text { Antibiotic }\end{array}$ & $4.5 \times 3.0$ & Oflox & Pneumococcus & yes & 3 & $8.0 \times 8.0$ & graft failed & PK (@12/7) \\
\hline $2 / 27$ & 70 & $\mathrm{~F}$ & HSV & $\begin{array}{l}\text { Steroid } \\
\text { Antibiotic }\end{array}$ & $5.0 \times 4.5$ & Oflox & Bacillus sp & yes & 2 & $5.0 \times 4.5$ & perforation & PK (@2/7) \\
\hline $2 / 29$ & 67 & M & & & $1.0 \times 3.0$ & Cef and gent & $\begin{array}{l}\text { Coagulase negative } \\
\text { Staphylococcus }\end{array}$ & yes & 16 & $3.5 \times 2.0$ & perforation & $\begin{array}{l}\text { self sealed, but } \\
\text { PK (@1/12) }\end{array}$ \\
\hline $2 / 24$ & 41 & $\mathrm{~F}$ & blocked lacrimal duct & & $3.5 \times 3.0$ & Oflox & Diphtheroids sp & yes & 4 & $0.5 \times 0.5$ & new infiltrates & healed \\
\hline $2 / 8$ & 88 & $\mathrm{~F}$ & $\mathrm{PK}(\mathrm{BK})$ & $\begin{array}{l}\text { Steroid } \\
\text { Antibiotic }\end{array}$ & $7.0 \times 3.0$ & Cef and gent & $\begin{array}{l}\text { Capnocytophage } \\
\text { ochracea }\end{array}$ & yes & 3 & $8.5 \times 3.0$ & graft failed & PK(@6/52) \\
\hline $2 / 9$ & 82 & $M$ & PK (BK) & Steroid & $4.0 \times 3.0$ & Cef and gent & $\begin{array}{l}\text { Coag neg staph } \\
\text { and } X \text { maltophillia }\end{array}$ & $\begin{array}{l}\text { yes } \\
\text { no }\end{array}$ & 3 & $5.0 \times 4.0$ & graft failed & PK (@4/7) \\
\hline $2 / 26$ & 79 & M & & & $1.0 \times 5.0$ & Cef and gent & Coag neg staph & no & 5 & $4.0 \times 1.0$ & $\begin{array}{l}\text { extended } \\
\text { centrally }\end{array}$ & healed \\
\hline $1 / 24$ & 70 & M & PK (HSV) & Steroid & $2.5 \times 3.0$ & Cef and gent & Ps aeruginosa & no & 2 & $2.5 \times 3.0$ & slow healing & conj flap \\
\hline $1 / 40$ & 78 & $\mathrm{~F}$ & BK (rubeosis) & Antibiotic & $6.0 \times 8.0$ & Oflox & Ps aeruginosa & yes & 6 & $6.0 \times 8.0$ & deteriorated & eviscerated \\
\hline
\end{tabular}




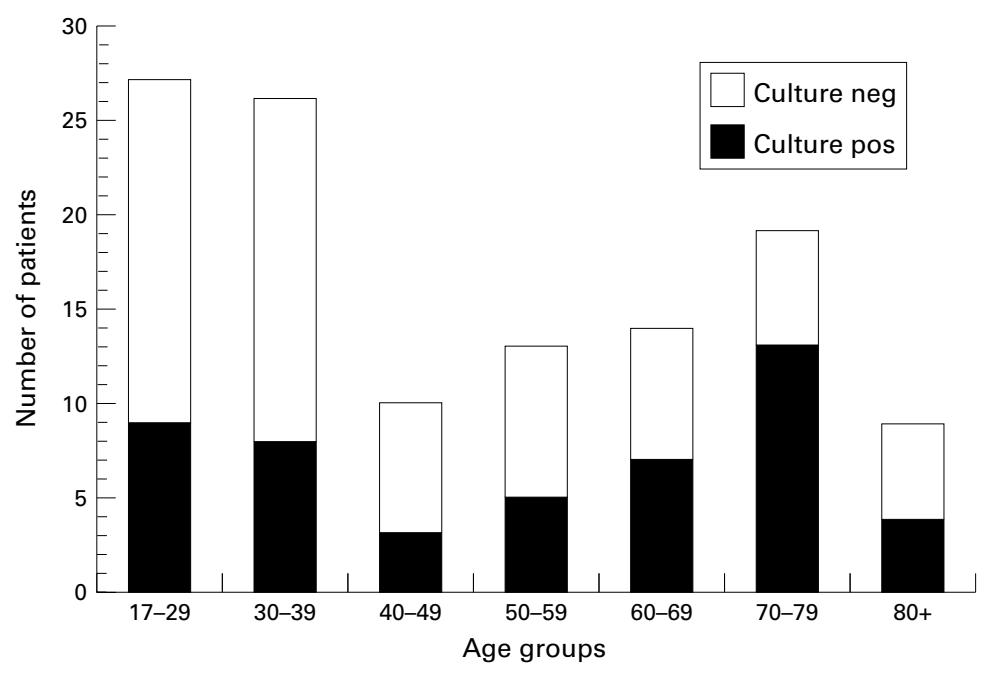

Figure 1 Age distribution and culture results of patients with suspected microbial keratitis.

Table 3 Significant predictors for primary treatment failure of suspected microbial keratitis

\begin{tabular}{|c|c|c|c|c|c|c|}
\hline \multirow{2}{*}{ Characteristics } & & \multicolumn{2}{|c|}{ Primary treatment failure } & \multirow[b]{2}{*}{ Risk ratio } & \multirow[b]{2}{*}{$95 \% C I$} & \multirow[b]{2}{*}{$p$ Value } \\
\hline & & No & $\%$ & & & \\
\hline \multicolumn{7}{|c|}{ "Crude" estimates of risk ratio with no adjustment for confounding factors } \\
\hline \multicolumn{2}{|c|}{ Culture positive ulcers $>5 \mathrm{~mm}^{2}$} & $11 / 26$ & 42.3 & 12.8 & $3.9-43.1$ & $<0.001$ \\
\hline \multicolumn{2}{|c|}{ Other ulcers } & $3 / 92$ & 3.3 & & & \\
\hline \multirow{2}{*}{\multicolumn{2}{|c|}{$\begin{array}{l}\text { Age } 60+\text { years } \\
\text { Age }<60 \text { years }\end{array}$}} & $13 / 42$ & 40.0 & & $3.2-173.6$ & $<0.001$ \\
\hline & & $1 / 76$ & 1.3 & 23.5 & & \\
\hline \multicolumn{2}{|c|}{ Previous corneal disease } & $11 / 38$ & 28.9 & 7.7 & $2.3-26.1$ & $<0.001$ \\
\hline \multicolumn{2}{|c|}{ No previous corneal disease } & $3 / 80$ & 3.8 & 1.1 & & \\
\hline \multicolumn{2}{|c|}{ Topical steroid treatment } & $6 / 19$ & 31.6 & 3.9 & $1.5-10.0$ & 0.01 \\
\hline \multicolumn{2}{|c|}{ No steroid } & $8 / 99$ & 8.1 & & & \\
\hline \multirow{2}{*}{\multicolumn{2}{|c|}{$\begin{array}{l}\text { Hypopyon present } \\
\text { No hypopyon }\end{array}$}} & $5 / 15$ & 33.3 & \multirow[t]{2}{*}{3.8} & $1.5-9.9$ & 0.017 \\
\hline & & 9/103 & 8.7 & & & \\
\hline \multicolumn{3}{|c|}{ Variables in regression model } & \multicolumn{2}{|c|}{ Adjusted risk ratio } & $95 \% C I$ & $p$ Value \\
\hline \multicolumn{7}{|c|}{ Results of multiple regression analysis for risk factors with adjustment for confounding factors } \\
\hline \multirow{2}{*}{\multicolumn{5}{|c|}{$\begin{array}{ll}\text { Culture positive ulcers }>5 \mathrm{~mm}^{2} v \text { other ulcers } & 5.5 \\
\text { Age } 60+v \text { age }<60 \text { years } & 11.0\end{array}$}} & $1.4-20.8$ & 0.013 \\
\hline & & & & & $1.3-92.1$ & 0.027 \\
\hline \multicolumn{7}{|c|}{$\begin{array}{l}\text { Further adjustment for confounding effect of other factors one at a time did not materially change } \\
\text { the results. }\end{array}$} \\
\hline \multicolumn{7}{|l|}{ Table 4} \\
\hline \multirow[b]{2}{*}{ Ulcer size } & & \multicolumn{2}{|c|}{ Age $<60$ years } & \multicolumn{3}{|c|}{ Age group $60+$ years } \\
\hline & Culture & No & $\begin{array}{l}\text { Primary treatment } \\
\text { failure }\end{array}$ & No & $\begin{array}{l}\text { Primary tre } \\
\text { failure }\end{array}$ & eatment \\
\hline \multirow[t]{2}{*}{ Large $\left(5+\mathrm{mm}^{2}\right)$} & Positive & 7 & $1(14.3 \%)$ & 19 & $10(52.6 \%)$ & \\
\hline & Negative & 3 & 0 & 6 & $1(16.7 \%)$ & \\
\hline \multirow[t]{2}{*}{ Small $\left(<5 \mathrm{~mm}^{2}\right)$} & Positive & 18 & 0 & 5 & $2(40.0 \%)$ & \\
\hline & Negative & 48 & 0 & 12 & 0 & \\
\hline
\end{tabular}

models. Multiple regression analysis using Poisson models was used to estimate the relative risk of the main prognostic factors.

\section{Results}

Table 1 summarises the baseline clinical characteristics of the patients who failed primary treatment (14 patients, $12 \%$ ), had slow healing (17 patients, 14\%) or indolent ulcers (15 patients, $13 \%$ ). Further details of the clinical characteristics of the patients who failed primary treatment are described in Table 2. The age, demographic, and culture results are shown in Figure 1.

Multivariate analysis identified large culture positive ulcers in patients 60 years or older as the most significant risks for primary treatment failure (Tables 3 and 4). Surgery was required by $10 / 14$ patients who failed primary therapy, all of whom were 60 years or older $(\mathrm{p}<0.0001)$ and the significant prognostic indicators identified for this subgroup were culture positive ulcers and previous corneal disease (Table 5).

Significant prognostic indicators of slow healing were previous ocular disease and a positive culture (Table 6). However, if previous ocular disease was divided into the various diagnoses, ulcer size larger than $5 \mathrm{~mm}^{2}$ predominated as the sole predictive factor ( RR $4.35,95 \%$ CI $1.65-11.76, p=0.004)$. The significant prognostic indicators of indolent ulceration were any previous ocular disease or topical steroid use at diagnosis (Table 7). The main predictor for a culture positive ulcer was large ulcer size (Table 8).

\section{Discussion}

A positive culture had prognostic value in the management of microbial keratitis in the elderly, regardless of the organism cultured or sensitivity data. However, the results also suggest that microbial investigation of small ulcers was rarely useful for the purpose of predicting prognosis, especially for young patients.

The value of culturing ulcers as part of the initial management of microbial keratitis was questioned by McDonnell et al following their survey of 64 general ophthalmologists practising in California. ${ }^{12}$ Only $14(23 \%)$ considered a corneal scrape was always necessary, the majority $(35,57 \%)$ considered a scrape only necessary for large ulcers. McDonnell took the debate further in his editorial which outlined three approaches to the issue: (i) scrape all ulcers (as is the current expert opinion), (ii) scrape none initially and scrape those that fail primary empirical therapy, (iii) scrape only those patients who have severe ulcers or a history and appearance suspicious for an unusual pathogen. ${ }^{11}$ Although our results would support McDonnell's latter approach, the $70 \%$ reduction in our number of microbiological investigations, would also have resulted in the loss of 23/49 (47\%) of our culture positive specimens. This would seriously dilute the usefulness of the culture data for epidemiological purposes. For an appropriate empirical therapy, it is necessary to collect local contemporaneous data about the presenting causative organisms of microbial keratitis. All our primary treatment failures were culture positive, but there is no guarantee that a culture subsequent to primary treatment would have provided the same results.

Our results confirm the original observation by Coster and Badenoch ${ }^{9}$ that ulcer size was an important risk factor. ${ }^{10}$ In their retrospective study Blanton et al also reported that increasing ulcer size was significantly correlated with failure of therapy (although the statistical analysis in their report was incomplete and underestimated the effect)..$^{10}$

A bimodal age distribution of patients presenting with microbial keratitis was reported in three previous papers, with the $60+$ year old group predominating..$^{7-9}$ The present study had a larger preponderance of younger patients (Fig 1) who were more likely to be 
Table 5 Significant predictors for requiring surgery following failure of primary treatment of suspected microbial keratitis

\begin{tabular}{|c|c|c|c|c|c|}
\hline \multirow[b]{2}{*}{ Characteristics } & \multicolumn{2}{|c|}{$\begin{array}{l}\text { Primary treatment failure } \\
\text { requiring surgery }\end{array}$} & \multirow[b]{2}{*}{ Risk ratio } & \multirow[b]{2}{*}{$95 \% C I$} & \multirow{2}{*}{$\stackrel{p}{\text { Value }}$} \\
\hline & No & $\%$ & & & \\
\hline \multicolumn{6}{|c|}{ "Crude" estimates of risk ratio with no adjustment for confounding factors } \\
\hline Age $60+$ years & $10 / 42$ & 40.0 & - & - & $<0.001$ \\
\hline Age $<60$ years & $0 / 76$ & 0.0 & & & \\
\hline Culture positive ulcer $>5 \mathrm{~mm}^{2}$ & $7 / 26$ & 26.9 & 8.3 & $2.3-29.7$ & $<0.001$ \\
\hline Other ulcers & $3 / 92$ & 3.3 & & & \\
\hline Hypopyon present & $5 / 15$ & 33.3 & 6.9 & $2.3-20.9$ & 0.003 \\
\hline Hypopyon absent & $5 / 103$ & 4.9 & & & \\
\hline Previous corneal disease & $8 / 38$ & 21.1 & 8.4 & $1.9-37.8$ & 0.002 \\
\hline No previous corneal disease & $2 / 80$ & 2.5 & & & \\
\hline Topical steroids before diagnosis & $5 / 19$ & 26.3 & 5.2 & $1.7-16.3$ & 0.01 \\
\hline No prior steroid & $5 / 99$ & 5.1 & & & \\
\hline \multicolumn{6}{|l|}{ In the age group $60+$ years old } \\
\hline Culture positive ulcers & $9 / 24$ & 37.5 & 6.7 & $0.94-48.6$ & 0.026 \\
\hline Other ulcers & $1 / 17$ & 5.6 & & & \\
\hline Previous corneal disease & $8 / 21$ & 38.1 & 4.0 & $0.96-16.7$ & 0.032 \\
\hline No previous corneal disease & $2 / 19$ & 9.5 & & & \\
\hline
\end{tabular}

In the 60+ year old group, presence of hypopyon was a borderline risk factor (RR 2.5 (0.9-7.1), exact $\mathrm{p}=0.117)$, as was the presence of large culture positive ulcers (RR 2.8 (0.8 9.5), exact $\mathrm{p}=0.143$ ). There were only 10 cases requiring surgery, all in the older age group. The small sample had little power in detecting significant predictors in regression analysis with adjustment for confounding factors, none was detected.

Table 6 Significant predictors for slow healing with treatment of suspected microbial keratitis

\begin{tabular}{lllllll}
\hline \multicolumn{5}{c}{ Slow healing } & & \\
\cline { 2 - 3 } Characteristics & No & $\%$ & Risk ratio & $95 \%$ CI & p Value \\
\hline "Crude” estimates of risk ratio with & no adjustment for confounding factors & & \\
Culture positive ulcer & $13 / 49$ & 26.5 & 4.58 & $1.59-13.2$ & 0.0016 \\
Culture negative & $4 / 69$ & 5.8 & & & \\
Any previous ocular disease & $16 / 62$ & 25.8 & 14.45 & $1.98-105.48$ & $<0.001$ \\
No previous ocular disease & $1 / 56$ & 1.8 & & & \\
\hline
\end{tabular}

Table 7 Significant predictors for indolent ulceration with treatment of suspected microbial keratitis

\begin{tabular}{|c|c|c|c|c|c|}
\hline \multirow[b]{2}{*}{ Characteristics } & \multicolumn{2}{|c|}{ Indolent ulceration } & \multirow[b]{2}{*}{ Risk ratio } & \multirow[b]{2}{*}{$95 \% C I$} & \multirow[b]{2}{*}{$p$ Value } \\
\hline & No & $\%$ & & & \\
\hline \multicolumn{6}{|c|}{ "Crude" estimates of risk ratio with no adjustment for confounding factors } \\
\hline Previous ocular disease & $14 / 62$ & 22.6 & 12.65 & $1.72-93.1$ & $<0.001$ \\
\hline No previous disease & $1 / 56$ & 1.8 & & & \\
\hline Topical steroids before diagnosis & $7 / 19$ & 36.8 & 4.56 & $1.88-11.08$ & 0.0027 \\
\hline No prior steroid use & $8 / 99$ & 8.1 & & & \\
\hline
\end{tabular}

Table 8 Significant predictors for positive culture with investigation of suspected microbial keratitis

\begin{tabular}{|c|c|c|c|c|c|}
\hline \multirow[b]{2}{*}{ Characteristics } & \multicolumn{2}{|c|}{ Positive culture } & \multirow[b]{2}{*}{ Risk ratio } & \multirow[b]{2}{*}{$95 \% C I$} & \multirow[b]{2}{*}{$p$ Value } \\
\hline & No & $\%$ & & & \\
\hline \multicolumn{6}{|c|}{ Estimates of risk ratio with no adjustment for confounding factors } \\
\hline Ulcer size $5+\mathrm{mm}^{2}$ & $26 / 35$ & 74.3 & 2.68 & $1.80-3.99$ & $<0.001$ \\
\hline Ulcer size $<5 \mathrm{~mm}^{2}$ & $23 / 83$ & 27.7 & & & \\
\hline
\end{tabular}

contact lens users $(43 / 76,57 \%$ v $3 / 42,7 \%$ in the $60+$ group, $\mathrm{p}<0.0001)$. The diagnosis of suspected microbial keratitis in this group probably reflects the clinicians' concern about the well documented risk of microbial keratitis in contact lens users. However, most of the lesions scraped in this group were not culture positive and may have been sterile infiltrated ulcers as previously described in contact lens users. $^{14}$ The finding by Blanton et al that contact lens use was a predictor of a good outcome may have been confounded by the age of the contact lens users in their study. ${ }^{10}$

Primary treatment failure varies between reports but recently McLeod et al ${ }^{15}$ highlighted the importance of prescribing the appropriate antibiotics as primary therapy. Although many of the numbers in their paper did not add up, they reported that $8 / 26(31 \%)$ of the patients referred for further management were definitely prescribed inappropriate therapy and that $8 / 11(73 \%)$ with poor initial therapy failed treatment compared with $8 / 41$ $(20 \%)$ given appropriate initial therapy. They also found that $26 / 34(77 \%)$ of ulcers that failed previous antibiotic treatment were subsequently culture positive but many of these patients were on an inappropriate antibiotic. ${ }^{15}$ In 1987 Coster and Badenoch ${ }^{9}$ reported 22/78 $(28 \%)$ treatment failures giving poor outcome from a series that had a large number of primary care patients and Gudmundsson et $a l^{8}$ reported $31 / 175(18 \%)$ of their series of culture positive cases (selected from about 673 corneal cultures between 1977-81) had a major complication with 27 requiring surgery. In another more recent report concerning mainly primary care patients, McLeod et al reported $3 / 81,4 \%(3 / 56,5 \%$ of the culture positive cases) failed primary treatment, all of whom occurred in the severe ulceration group (41 patients). ${ }^{13}$ We found a primary treatment failure of $14 / 118,12 \%(13 / 39,33 \%$ of the culture positive cases) in our prospective study of predominately primary care patients. It is difficult to compare the efficacy of the treatments used in these studies because of the differences in the age demographics and differences in the rate of fungal isolation.

Poor healing not surprisingly was associated with previous ocular disease, prior steroid treatment, and large ulcers. However, a positive culture result alone was predictive of poor healing regardless of the organism obtained, suggesting that such information is useful when patients present with large ulcers $(>5.0$ $\mathrm{mm}^{2}$ ). Stern and Buttross presented a comprehensive discussion of the role of topical corticosteroids in microbial keratitis. ${ }^{16} \mathrm{Al}-$ though steroids may potentially worsen the outcome of microbial keratitis if used too early, we did not find steroid use was a significant risk factor for primary treatment failure in our group of patients after adjustment for confounding effects of age, ulcer size, and culture result. Prior steroid use was a risk for indolent ulceration possibly as a result of inhibition of wound healing, or of the nature of the underlying ocular problem which was also an associated risk. These findings have management implications for patients with surface disease and/or who have been using topical steroids. Such patients may benefit from modified therapeutic measures to ensure prompt ulcer epithelialisation; these may include avoidance of toxic antibiotic therapy (that is, the aminoglycosides) where possible, treatment of surface disease such as dry eye, and early use of protective ptosis with botulinum toxin, eyelid splints, or other temporary tarsorrhaphy.

As Coster and Badenoch pointed out, a poor outcome still occurs even when the patient presents early, appropriate empirical therapy is initiated, the causative organism is identified, and drug susceptibility is confirmed. ${ }^{9}$ A rationalisation of the use of corneal scrape and 
microbiological culture may be justified, but at the cost of diluting local contemporaneous data upon which empirical primary treatment is based, and with the loss of prognostic information about the risk of primary treatment failure and poor healing.

The authors have no proprietary interest in the products used in this study. Presented in part at the World Corneal Congress IV Orlando USA 1996

\section{Ofloxacin Study Group}

Fellows in corneal and external eye disease:

Bruce Allan MD FRCS, ${ }^{1}$ Romain DeCock MB BS FRCOphth, ${ }^{1}$ Hosam El Kassaby MB BS FRCOphth, ${ }^{1}$ Nigel Morlet MB BS FRACO FRACS, ${ }^{1}$ Carlos Pavesio MD. ${ }^{1}$

Registrars in ophthalmology:

Jeremy Butcher MB BS FRCOphth, ${ }^{2}$ Roger Baer MB BS FRCOphth, ${ }^{1}$ David Broadway MD FRCOphth, Graham Duguid MD FRCS, ${ }^{1}$ Peter Heyworth MB BS FRCOphth, ${ }^{1}$ Chris Jenkins MB BS MRCP FRCS, ${ }^{1}$ Genevieve Larkin MB BCh FRCOphth, ${ }^{1}$ Andrew McNaught MB BS FRCOphth.

Consultant ophthalmologists:

John Dart MA DM FRCS, ${ }^{1}$ Linda Ficker MD FRCOphth, ${ }^{1}$ Andrew Tullo MD FRCOphth. ${ }^{2}$

Epidemiologist:

Darwin Minassian MB BS MSc FRCS. ${ }^{3}$

Microbiologists:

Malcolm Armstrong FIBMS, ${ }^{5}$ Melville Matheson BSc. ${ }^{4}$

Affiliations:

1 Moorfields Eye Hospital.

2 Manchester Royal Eye Hospital.

3 International Centre of Eye Health, Institute of Ophthalmology, London.
4 Department of Pathology, Institute of Ophthalmology, London.

5 Department of Microbiology, Central Manchester Health Care Trust.

1 Ofloxacin Study Group.

2 O'Brien TP, Maguire MG, Fink NE, et al and the Bacterial Keratitis Study Research Group. Efficacy of ofloxacin vs cefazolin and tobramycin in the therapy for bacterial keratitis. Arch Ophthalmol 1995;113:1257-65.

3 Parks DJ Abrams DA, Sarfarazi FA, et al. Comparison of ciprofloxacin to conventional antibiotic therapy in the treatment of ulcerative keratitis. Am f Ophthalmol 1993; 115:471-7.

4 Jacobson JA, Call NB, Kasworm EM, et al. Safety and efficacy of topical norfloxacin vs tobramycin in the tecular infections. Antimicrob Agents Chemother 1988;32:1820-4.

5 Wilhelmus KR, Hyndiuk RA, Caldwell DR, et al. Ciprofloxacin $0.3 \%$ ophthalmic ointment in the treatment of bacterial keratitis. Arch Ophthalmol 1993;111:1210-8.

6 Leibowitz HM. Clinical evaluation of ciprofloxacin $0.3 \%$ ophthalmic solution for the treatment of bacterial keratitis. Am f Ophthalmol 1991;112(Suppl):34s-47s.

7 Musch DC, Sugar A, RF Meyer. Demographic and predisMusch DC, Sugar A, RF Meyer. Demographic and predis-
posing factors in corneal ulceration. Arch Ophthalmol 1983; posing factors

8 Gudmundsson OG, Ormerod LD, Kenyon KR, et al. Factors influencing the predilection and outcome in bacterial keratitis. Cornea 1989;8:115-21.

9 Coster DJ, Badenoch PR. Host, microbial, and pharmacological factors affecting the outcome of suppurative keratitis. Br F Ophthalmol 1987;71:96-101.

10 Blanton CL, Rapuano CJ, Cohen EJ, et al. Initial treatment of microbial keratitis. CLAO f 1996;22:136-40.

11 McDonnell PJ. Empirical or culture-guided therapy for microbial keratitis? A plea for data. Arch Ophthalmol 1996; 114:84-7.

12 McDonnell PJ, Nobe J, Gauderman WJ, et al. Community care of corneal ulcers. Am $\mathcal{F}$ Ophthalmol 1992;114:531-8.

13 McLeod SD, Kolahdouz-Isfahani A, Rostamian K, et al. The role of smears, cultures and antibiotic sensitivity testing in the management of suspected infectious keratitis. Ophthalmology 1996;103:23-8.

Ophthalmology 1996;103:23-8.
4 Bernauer W, Dart JKG. Aseptic keratitis associated with Bernauer W, Dart JKG. Aseptic keratitis associated
contact lenses. Ophthalmol Clin N Am 1994;7:661-7. contact lenses. Ophthalmol Clin N Am 1994;7:661-7. The
15 al. The McLeod SD, LaBree LD, Tayyanipour R, et al. The
importance of initial management in the treatment of severe infectious corneal ulcers. Ophthalmology 1995;102: 1943-8

16 Stern GA, Buttross M. Use of corticosteroids in combination with antimicrobial drugs in the treatment of infectious corneal disease. Ophthalmology 1991;98:847-53. 